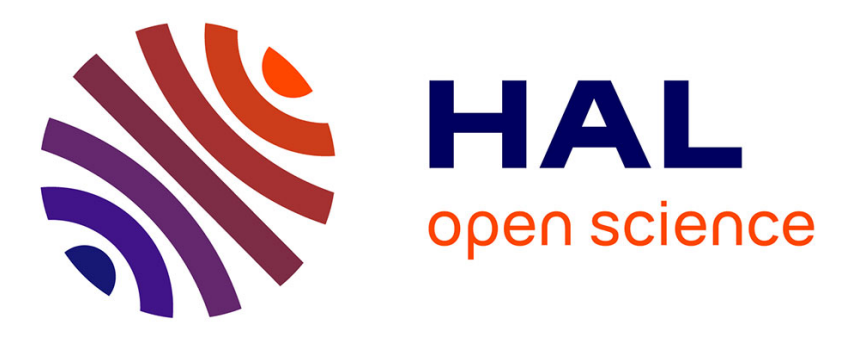

\title{
Mid-Infrared Supercontinuum Generation in Germanium-on-Silicon Waveguides
}

Alberto Della Torre, Milan Sinobad, Rémi Armand, Barry Luther-Davies, Pan Ma, Stephen Madden, David J Moss, Arnan Mitchell, Jean-Michel Hartmann, Vincent Reboud, et al.

\section{To cite this version:}

Alberto Della Torre, Milan Sinobad, Rémi Armand, Barry Luther-Davies, Pan Ma, et al.. Mid-Infrared Supercontinuum Generation in Germanium-on-Silicon Waveguides. Conference on Lasers and ElectroOptics/Pacific Rim 2020, Aug 2020, Sydney, Australia. pp.PDP_3, 10.1364/CLEOPR.2020.PDP_3 . hal-03295805

\section{HAL Id: hal-03295805 https://hal.science/hal-03295805}

Submitted on 22 Jul 2021

HAL is a multi-disciplinary open access archive for the deposit and dissemination of scientific research documents, whether they are published or not. The documents may come from teaching and research institutions in France or abroad, or from public or private research centers.
L'archive ouverte pluridisciplinaire HAL, est destinée au dépôt et à la diffusion de documents scientifiques de niveau recherche, publiés ou non, émanant des établissements d'enseignement et de recherche français ou étrangers, des laboratoires publics ou privés. 


\title{
Mid-Infrared Supercontinuum Generation in Germanium-on-Silicon Waveguides
}

\author{
Alberto Della Torre, ${ }^{1,6}$ Milan Sinobad, ${ }^{1}$ Rémi Armand, ${ }^{1}$ Barry Luther-Davies, ${ }^{2}$ Pan $M a,{ }^{2}$ Stephen \\ Madden, ${ }^{2}$ David J. Moss, ${ }^{3}$ Arnan Mitchell, ${ }^{4}$ Jean-Michel Hartmann, ${ }^{5}$ Vincent Reboud, ${ }^{5}$ Jean-Marc \\ Fedeli, ${ }^{5}$ Christelle Monat, ${ }^{1}$ and Christian Grillet ${ }^{1}$ \\ ${ }^{1}$ Université de Lyon, Institut des Nanotechnologies de Lyon (INL), 69131 Ecully, France \\ ${ }^{2}$ Laser Physics Centre, Australian National University, Canberra, ACT 0100, Australia \\ ${ }^{3}$ Optical Sciences Centre, Swinburne University of Technology, Hawthorn, VIC 3122, Australia \\ ${ }^{4}$ School of Engineering, RMIT University, Melbourne, VIC 3001, Australia \\ ${ }^{5}$ Université Grenoble Alpes, CEA-Leti, 38054 Grenoble Cedex 9, France \\ ${ }^{6}$ e-mail : alberto.della-torre@ec-lyon.fr
}

\begin{abstract}
We report the first experimental supercontinuum generation (from 3.53 to $5.83 \mu \mathrm{m}$ ) in a pure germanium waveguide. By optimizing the design, we envision to generate a supercontinuum extending up to almost $10 \mu \mathrm{m}$. (C) 2020 The Author(s)
\end{abstract}

\section{Introduction}

In the last two decades, germanium has played a key role in group-IV photonics. Germanium was at first used in integrated photonic devices operating in the near-infrared [1,2]. More recently, however, the wide transparency window up to $15 \mu \mathrm{m}$ [3] and the theoretical prediction of attractive nonlinear properties [4] have led researchers to explore germanium as a promising material for mid-infrared (from 3 to $15 \mu \mathrm{m}$ ) photonics. In terms of fabrication, tremendous progress has been made in recent years, with several demonstrations of low-loss germanium on silicon waveguides in the mid-infrared region [1].

Mid-infrared devices can for instance be used for the detection and recognition of molecules, in particular organic species, with strong fundamental absorption lines in this band [3]. A broadband source, such as a supercontinuum, is a fundamental element for integrated sensing platforms since it allows for parallel detection of multiple gas species [5]. On-chip mid-infrared supercontinuum generation has been demonstrated in several group-IV platforms [5-8]. Supercontinuum generation up to $8.5 \mu \mathrm{m}$ has been demonstrated by our group in silicongermanium on silicon waveguides, reaching the onset of the absorption from the silicon substrate [7]. We have also demonstrated the possibility, with this platform, of precisely controlling the supercontinuum coherence properties [9,10]. Due to their a priori wider transparency windows [11], pure germanium on silicon waveguides are anticipated to overcome the current limits of other group-IV platforms. So far, however, supercontinuum generation in germanium waveguides has been limited to numerical demonstrations.

Here we report the first experimental demonstration of supercontinuum generation in a pure germanium waveguide. We pumped a $4.46 \mu \mathrm{m} \times 2.57 \mu \mathrm{m}$ cross-section germanium on silicon air-clad waveguide with $\approx 200 \mathrm{fs}$ pulses at $4.6 \mu \mathrm{m}$, generating a supercontinuum extending from 3.53 to $5.83 \mu \mathrm{m}$. Owing to the transparency of the atmosphere between 3 and $5 \mu \mathrm{m}$ and to the strong absorption of hazardous and greenhouse gases such as $\mathrm{CO}(\sim 4.5$ $\mu \mathrm{m}), \mathrm{CO}_{2}(4.2,4,3 \mu \mathrm{m})$ and $\mathrm{CH}_{4}(3.45 \mu \mathrm{m})[12]$, our source has potential applications in free-space communications and environmental monitoring.

\section{Supercontinuum Generation}

A $4.46 \mu \mathrm{m}$ wide, $2.57 \mu \mathrm{m}$ thick air-clad germanium on silicon waveguide (fig. 1a inset) was designed to have low dispersion beyond $4 \mu \mathrm{m}$ (fig. 1a). We measured propagation losses of $\approx 1.25 \mathrm{~dB} / \mathrm{cm}$ between 3.5 and $4.5 \mu \mathrm{m}$.

Our nonlinear characterization of the platform suggested that the supercontinuum generation would be optimized when pumped at long wavelengths. Supercontinuum generation was achieved by pumping the waveguide with $\approx 200 \mathrm{fs}$ TE polarized pulses from a mid-infrared MIROPA-fs optical parametric amplifier at a repetition rate of $63 \mathrm{MHz}$. By pumping at $4.6 \mu \mathrm{m}$ (currently, the longest wavelength achievable by the MIROPAfs) in the normal dispersion regime, we obtained the spectra shown in fig $1 \mathrm{~b}$. When pumped with $22 \mathrm{~mW}$ coupled average pump power (corresponding to $3.3 \mathrm{~kW}$ coupled peak power), a $2.3 \mu \mathrm{m}$ bandwidth $(3.53-5.83 \mu \mathrm{m})$ at -30 $\mathrm{dB}$ level was achieved. Our modeling work shows that this long wavelength boundary is mainly limited by the high free-carrier absorption beyond $6 \mu \mathrm{m}$ [13]. Yet, our supercontinuum covers the 3-5 $\mu \mathrm{m}$ atmospheric transparency window, already making it particularly interesting for free-space communications and environmental monitoring.

We believe that improvements could be achieved if we could increase the pump wavelength to $5 \mu \mathrm{m}$. This should reduce the multiphoton absorption and therefore the generation of free-carriers [14]. Experimentally, our pump laser can be slightly modified to produce pulses around $5 \mu \mathrm{m}$. A $6 \mu \mathrm{m}$ wide by $2 \mu \mathrm{m}$ thick Ge waveguide 

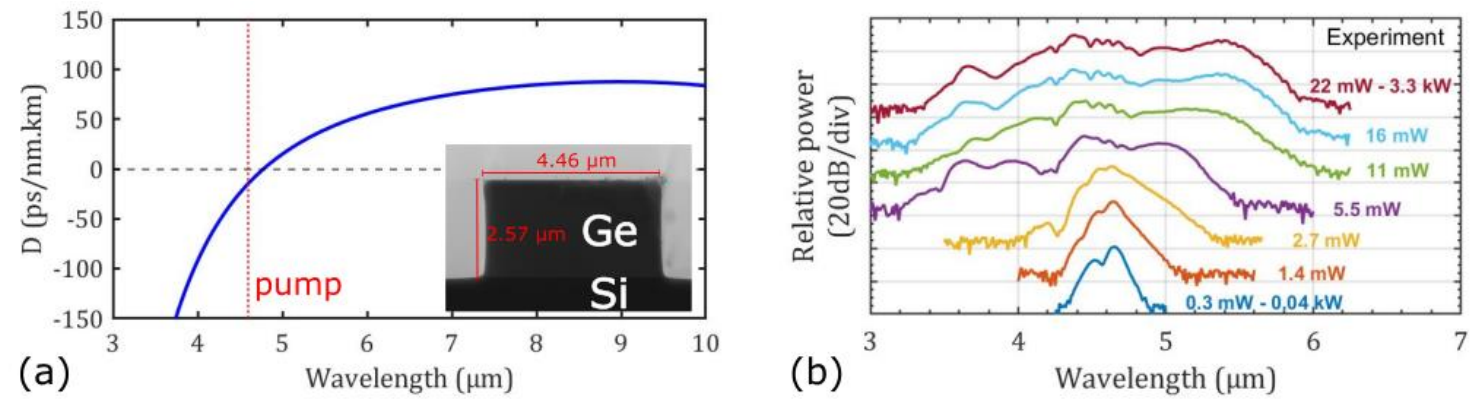

Figure 1: (a) Dispersion parameter of the germanium on silicon waveguide with a $4.46 \mu \mathrm{m} \times 2.57 \mu \mathrm{m}$ cross-section. A Scanning Electron Microscope image of the waveguide is shown in the inset. (b) Output spectra for different coupled average powers.

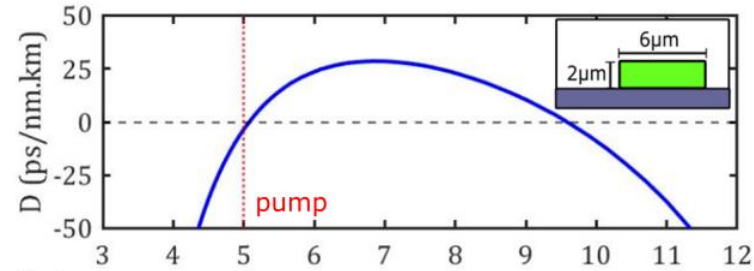

(a)

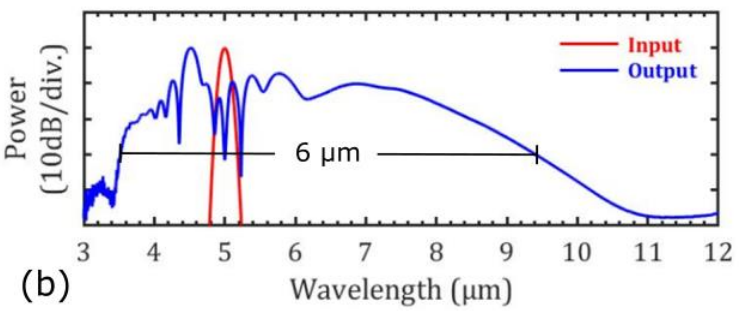

Figure 2: (a) Dispersion parameter of germanium on silicon waveguide with a $6 \mu \mathrm{m}$ x $2 \mu \mathrm{m}$ cross-section (inset). (b) Numerical input (red) and output spectra (blue) for a $1.2 \mathrm{~cm}$ long waveguide pumped with $4.5 \mathrm{~kW}$ coupled peak power.

(fig. 2 (a), inset) exhibits low dispersion from 4 to $11 \mu \mathrm{m}$ with zero dispersion at $5 \mu \mathrm{m}$ (fig. 2 (a)). With a $1.2 \mathrm{~cm}$ long waveguide pumped with a $4.5 \mathrm{~kW}$ coupled peak power, we numerically predict a supercontinuum extending over a $6 \mu \mathrm{m}$ bandwidth $(3.5-9.5 \mu \mathrm{m})$ at the $-30 \mathrm{~dB}$ level (fig. 2 (b)). These predictions will form the basis of our next experiments.

\section{Conclusion}

In conclusion, we have demonstrated the first experimental supercontinuum generation in a pure germanium waveguide. The supercontinuum covers the $3.53-5.83 \mu \mathrm{m}$ band. The multiphoton absorption and therefore the generation of free-carriers could be reduced by pumping at longer wavelengths, potentially enabling to generate a supercontinuum extending up to almost $10 \mu \mathrm{m}$.

Acknowledgments. We acknowledge the support of the International Associated Laboratory in Photonics between France and Australia (LIA ALPhFA), the Agence Nationale de la Recherche (MIRSICOMB, ANR-17-CE24-0028) and the European Research Council (ERC) under the European Union's Horizon 2020 program (GRAPHICS 648546).

\section{References}

[1] D. Marris-Morin et al., "Germanium-based integrated photonics from near- to mid-infrared applications," Nanophotonics 7, 1781-1793 (2018).

[2] V. Reboud et al., "Germanium based photonic components toward a full silicon/germanium photonic platform," Prog. Cryst. Growth Charact. Mater. 63, 1-24 (2017).

[3] R. Soref, "Mid-infrared photonics in silicon and germanium," Nat. Photonics 4, 495-497 (2010).

[4] N. K. Hon, R. Soref, and B. Jalali, "The third-order nonlinear optical coefficients of $\mathrm{Si}, \mathrm{Ge}$, and $\mathrm{Si}_{1-x} \mathrm{Ge}_{x}$ in the midwave and longwave infrared," J. Appl. Phys. 110, 011301 (2011).

[5] E. Tagkoudi et al., "Parallel gas spectroscopy using mid-infrared supercontinuum from a single Parallel gas spectroscopy using midinfrared supercontinuum from a single Si 3 N 4 waveguide," Opt. Lett. 45, 2195-2198 (2020).

[6] N. Singh, et al., "Midinfrared supercontinuum generation from 2 to $6 \mu \mathrm{m}$ in a silicon nanowire," Optica 2, 797 (2015).

[7] M. Sinobad, et al., "Mid-wavelength Infrared Supercontinuum Generation Spanning 1.4 Octaves in a Silicon-Germanium Waveguide," Optica 5, 360 (2018).

[8] N. Nader et al., "Infrared frequency comb generation and spectroscopy with suspended silicon nanophotonic waveguides," Optica 6, $1269-1276$ (2019).

[9] M. Sinobad et al., "Dispersion trimming for mid-infrared supercontinuum generation in a hybrid chalcogenide/silicon-germanium waveguide," J. Opt. Soc. Am. B 36, A98 (2019).

[10] M. Sinobad, et al., "High coherence at $\mathrm{f}$ and $2 \mathrm{f}$ of mid-infrared supercontinuum generation in silicon germanium waveguides," IEEE J. Sel. Top. Quantum Electron. 26, 1-8 (2019).

[11] G. Z. Mashanovich, et al., "Group IV mid-infrared photonics [ Invited ]," Opt. Mater. Express 8, 1040-1043 (2018).

[12] V. M. Lavchiev and B. Jakoby, "Photonics in the Mid-Infrared: Challenges in Single-Chip Integration and Absorption Sensing," IEEE J. Sel. Top. Quantum Electron. 23, (2017).

[13] M. Nedeljkovic, R. Soref, and G. Z. Mashanovich, "Predictions of free-carrier electroabsorption and electrorefraction in germanium," IEEE Photonics J. 7, (2015).

[14] D. Seo, et al., "Multiphoton absorption in germanium using pulsed infrared free-electron laser radiation," Phys. Rev. B - Condens. Matter Mater. Phys. 83, 1-6 (2011). 